\title{
Ciências e educação em museus no final do século XIX
}

The sciences and education in museums at the close of the nineteenth century
Maria Margaret Lopes

Professora do Instituto de Geociências Universidade Estadual de Campinas (Unicamp) Cidade Universitaria Zeferino Vaz Distrito de Barão Geraldo Caixa Postal 6152

13083-970 Campinas - SP - Brasil mmlopes@ige.unicamp.br

\section{Sandra Elena Murriello}

Doutoranda no Departamento de Geociências Aplicadas ao Ensino, Instituto de Geociências - Unicamp.
LOPES, M. M. e MURRIELLO, S. E.: Ciências e educação em museus no final do século XIX.

História, Ciências, Saúde - Manguinhos, v. 12 (suplemento), p. 13-30, 2005.

Nas últimas décadas do século XIX, os museus de história natural estabeleceram sólidas redes de comunicação entre si, com seus diferentes públicos conformando o processo internacional caracterizado como o 'movimento dos museus'. Nesse contexto de intercâmbios apresenta-se o discurso que pronunciou William H. Flower, em 1889, sobre os papéis que cabiam aos museus de história natural. Neste trabalho analisa-se a sua influência no recém-inaugurado Museo de La Plata, Argentina, integrante desse circuito de museus que se ampliava no período.

PALAVRAS-CHAVE: museus, educação, ciências.

LOPES, M. M. e MURRIELLO, S. E.: The sciences and education in museums at the close of the nineteenth century. História, Ciências, Saúde - Manguinhos, v. 12 (supplement), p. 13-30, 2005.

In the closing decades of the nineteenth century, natural history museums established solid communication networks, and their different audiences formed what became known as the 'museum movement'. It was within this context of exchange that William H. Flower made his 1889 speech on the roles natural history museums should play. The article analyzes his influence on Argentina's Museo de La Plata, a member of this then-expanding circuit of museums.

KEYWORDS: museums, education, sciences. 
As citações em espanhol de fins do século XIX correspondem à grafia da época.

\section{Introdução}

$\mathrm{H}_{\mathrm{r}}^{\mathrm{a}}$ á alguns anos, o conhecido historiador e museólogo mexicano Morales Moreno considerava que a historiografia sobre os museus não era valorizada pelos círculos acadêmicos da história institucional. Qualquer historiador que incursionasse no campo da historiografia aplicada à museologia - 'museohistória' - dificilmente encontraria eco para suas idéias. Só o conseguiria quando essa disciplina mostrasse seus recursos teóricos e metodológicos e aceitasse sem rubor suas limitações (Morales-Moreno, 1994, p. 13-4).

Nos últimos anos a situação tem-se modificado, e os museus vêm sendo objeto de investigação de diversas áreas disciplinares. Ademais, a própria museologia, como área de reflexão teórica e ação prática - essencialmente interdisciplinar-, já está consolidada não só no Brasil mas, também, com diferentes trajetórias, em diversos outros países latino-americanos.

Com a denominação 'museohistória', Morales-Moreno (1994) propôs-se a "abrir um espaço que refletisse [o museu] junto à historiografia da cultura, a etno-história, a sociologia do conhecimento e a antropologia social". Para isso, inicia seu trabalho justamente com o levantamento de fontes documentais e análise dos museus mexicanos. Segundo o autor, tem faltado aos investigadores que tratam da reconstrução histórica da cultura mexicana uma antologia documental que ofereça informações e idéias sobre "uma outra história silenciosa: a que se ocupa da acumulação significativa de objetos dentro de um espaço museográfico" (Morales-Moreno, 1994, p. 14, 19) . O aprofundamento teórico-metodológico sobre história dos museus, no caso deste artigo, no que se refere a aspectos comunicativos, expositivos educacionais e científicos, se apresenta como uma necessidade. Já existe uma vasta literatura interdisciplinar internacional em constante ampliação nestes últimos anos, mas ainda muito pouco considerada no Brasil, sobre aspectos históricos das instituições museológicas, que pode oferecer quadros referenciais fundamentais para esse tipo de análise.

O conceito de 'museohistória', embora não muito mais explicitado, é indicador de uma postura a ser compartilhada, mas também a ser problematizada, porque, apesar de Morales-Moreno não a mencionar, inegavelmente a idéia nos remete à obra clássica de George Brown Goode (1889) e a um tipo de historiografia que não necessariamente nos convém adotar.

George Brown Goode, que se tornaria o proeminente secretário assistente da Smithsonian Institution e responsável pelo seu Museu Nacional, apresentou o artigo 'Museum-history and museums of history' no $3^{\text {th }}$ Annual Meeting da American Historical Association, em dezembro de 1888, em Washington, que se notabilizaria por ser considerado o primeiro formalmente publicado so- 
1 Para o caso

brasileiro, é exemplar no mesmo sentido a retórica de Ladislau Netto na direção do Museu Nacional do Rio de Janeiro (Lopes, 1997). bre a história dos museus norte-americanos e por vir a ser profusamente mencionado na literatura sobre o tema, na época.

Nesse artigo, em que discute o lema do American Museum of Natural History - 'For the people, for education, for science' - para o caso norte-americano, Goode desconsiderou o passado museológico dos Estados Unidos, afirmando que os museus anteriores à década de 1870 reuniam objetos ao acaso, sem qualquer preocupação científica ou educacional, consistindo em meros espetáculos destinados à diversão pública. Seus seguidores se multiplicaram pelos museus de todo o mundo e não faltaram ecos de concepções semelhantes na América Latina, ${ }^{1}$ onde as últimas décadas do século XIX também assistiram a uma revitalização das instituições museológicas.

Identificada como 'criticismo profissional' por Oroz (1990), a visão de Goode exerceu profunda influência no pequeno corpus de historiografia dos museus norte-americanos. Metodologicamente inapropriadas, porque não se basearam em fontes primárias ou mesmo secundárias, tais investigações desprezaram o primeiro século de história dessas instituições.

Não havia um movimento formal de museus anterior a 1870. Nenhuma organização profissional fora formada, nenhuma revista oficial fora publicada, não havia porta-vozes oficiais de museus. No entanto, o conjunto de proprietários e diretores de museus já tinha estabelecido sólidas redes de comunicação entre si, "simultaneamente influenciados pelos mesmos fatores culturais e resultava que estavam fazendo as mesmas coisas, no mesmo momento pelos mesmos motivos" (Oroz, 1990, p. 3). Desmistificando as idéias que datavam das últimas décadas do século XIX - a origem do denominado por Coleman (1939) 'movimento de museus' - e discutindo o papel dos museus na construção da nação - o compromisso americano - de 1740 a 1870, Oroz destaca a importância que essas instituições tiveram na educação do público e na investigação científica, diante da consolidação das classes médias urbanas e da emergência da profissionalização.

Avaliações críticas recentes (Levinton e Aldrich, 2000), que consideram tanto o trabalho de Oroz como o de Sheets-Pyenson (1988), e ainda análises que atualizam os estudos de Limoges (1980) para o Muséum de Paris (Schnitter, 1996) e que não visam a tirar os méritos desses trabalhos, vêm chamando a atenção para a importância de se avançar em estudos sobre os museus que, recuperando as diferentes fases de suas histórias, considerem também em maior detalhe as especificidades de seus diferentes momentos.

Nesse sentido, revela-se bastante instigante pensar os museus como locais em que a cultura material é elaborada, exposta, comunicada e interpretada, como propõe Susan Pearce (1989), analisando os 'sistemas museais' - os diferentes contextos pelos quais 
esse tipo de instituição passou em sua história (Brefe, 2000). Aprofundar a análise dos diferentes 'sistemas museais' através dos quais se conformaram os museus do século XIX, incorporando considerações de ordem política, ideológica, estrutural, científica, educacional, pressupõe também, acrescentamos nós, refletir sobre as próprias coleções e as redes sociais que se conformaram em torno delas. Isto porque as coleções museológicas acumuladas dão acesso às escolhas feitas no passado, e suas exibições são formas privilegiadas de narrar publicamente esse passado.

Tratar os museus sob tal enfoque envolve identificar e desenvolver abordagens teóricas e históricas que possam auxiliar esses processos de análise, buscando compreender a natureza das coleções, o que elas são, por que teriam sido feitas, o que poderiam vir a ser, os papéis que couberam aos curadores e aos públicos, a natureza das interações que se processaram entre esses conjuntos de elementos (Pearce, 1989). Perspectivas que identificamos com as discussões também propostas por Lorraine Daston (1988) quando, discutindo a 'sensibilidade fatual' nas origens de coleções e construção das ciências modernas, perguntava-se até que ponto as coleções foram marginais nesses processos, em que a promoção da causa da história natural apoiou-se justamente nos materiais de referência. Suas perguntas - quem coletou, o quê, quando e por quê, devidamente contextualizadas - são as que teremos de repetir se queremos compreender os processos contemporâneos de construção de museus científicos.

Delimitar aqui nossas considerações sobre ciências e educação em museus, nas últimas décadas do século XIX e nas primeiras do século XX, não significa desconsiderar contextos anteriores, que podem contribuir para explicitar mais claramente demarcações internas ao próprio período em estudo. De fato, há uma necessidade fundamental de melhores caracterizações de propostas de periodizações para a história dos museus na América Latina, até mesmo para se precisar o entendimento da idéia de 'movimento de museus'. Embora periodizações sejam temas recorrentes na literatura internacional sobre o assunto, estes foram ainda pouco aprofundados, quer na museologia brasileira, quer na da América Latina. Pensando então em 'sistemas museais', mais do que em divisões cronológicas, períodos de administrações de determinados diretores, critérios propostos de forma anacrônica, interessa analisar os critérios demarcadores - e suas mudanças - de permanência de concepções, escolhas de coleções, prioridades de investigações e de construções de redes de sociabilidade, pelas quais coleções, catálogos, investigações viajaram entre os construtores de museus.

Embora o 'movimento dos museus' não tenha se originado, quer nos Estados Unidos, quer na América Latina, nas últimas décadas do século XIX (Lopes, 2002), sem dúvida nesse período os museus 
estabeleceram sólidas redes de comunicação entre si, com seus diferentes públicos, e integraram-se aos processos internacionais que Laurence Vail Coleman (1939), diretor da American Association of Museums, caracterizou como o 'movimento dos museus'.

Analisando o panorama mundial dos museus entre as últimas décadas do século XIX e as primeiras do século XX, Coleman (1929) considerou a expansão sem precedentes dos museus de todos os tipos, por todos os continentes, como um verdadeiro movimento social, marcado pelo estabelecimento de amplas redes de intercâmbios, que puseram em contato, de diferentes modos e em diferentes circunstâncias, os museus de todo o mundo. Coleman já incluía os museus da América Sul nesse movimento, uma vez que havia viajado, no final da década de 1920 , por praticamente toda a região e elaborado um catálogo com descrições sucintas do mundo dos museus sul-americanos.

De fato, além dos intercâmbios das mais variadas ordens, até mesmo formalmente diversos museus latino-americanos aderiram à American Association of Museums, como os anais do seu congresso inaugural de 1906 atestam. Em diversas ocasiões, os museus latino-americanos foram referidos na Museums Association britânica. Nesses veículos de integração, que foram essas associações e seus periódicos, durante o período de 1898 a 1906, houve também breves notas, notícias de páginas inteiras, comentários sobre os trabalhos realizados e as publicações editadas pelos museus de Valparaíso, La Plata, Buenos Aires, San José da Costa Rica, Paulista e Paraense do Brasil.

Por essas amplas redes de comunicação, as coleções, os catálogos, os pesquisadores, os conceitos e as inovações viajavam cada vez mais rapidamente pelo circuito dos museus. Passaram assim a integrar uma verdadeira tradição de viagens. Seus catálogos começaram a classificar os próprios museus, a construir tipologias, a comparar os próprios museus entre si em seus processos de cooperação e disputas por hegemonias científicas, sociais, políticas - de caráter nacional, regional e internacional. Nesse processo, discursos de figuras proeminentes eram rapidamente traduzidos, divulgados e discutidos, servindo de base retórica ou concreta para reorganizações de museus, pedidos de mais verbas e disputas políticas.

Se já salientamos a importância das redes de comunicação museológica estabelecidas entre instituições latino-americanas, importa aqui ressaltar um aspecto específico dos numerosos intercâmbios internacionais mantidos com museus europeus e norte-americanos. Trata-se justamente dos quadros referenciais adotados para a organização das exposições, dos modelos internacionais em que se apoiaram as sucessivas propostas de organização dos museus, das narrativas que os diretores construíram de seus próprios museus e dos desdobramentos dessas propostas em suas musealizações locais. 
Muitos dos registros dessas formas privilegiadas de se narrar o passado, das escolhas expositivas feitas, só chegaram até nós em fragmentos conservados em catálogos, guias de exposições, impressões de visitantes e, eventualmente, imagens. Assim, para contribuir para o entendimento do significado dos processos que caracterizaram o 'movimento de museus' por todo o mundo em sua dinâmica latino-americana, no que se refere a como esses museus se integraram a tais amplas redes de comunicação e intercâmbios, tomamos como objeto inicial de análise o artigo 'The museums of Natural History', de William H. Flower - diretor do Departamento de História Natural do British Museum (1884-1898) e presidente da British Association for the Advancement of Science na época. Consideramos também aspectos da proposta expositiva inicial do Museo de La Plata, Argentina, expressa no artigo 'Rápida ojeada sobre su fundación y desarrollo', de Francisco Pascásio Moreno idealizador e diretor do museu (1884-1906). Ambos os trabalhos foram publicados no primeiro volume da Revista del Museo de La Plata (1890-1), periódico que divulgou os trabalhos científicos da instituição.

\section{Por que Moreno publicou Flower?}

Em 11 de setembro de 1889, em Newcastle-Upon-Tyne, William H. Flower inaugurou sua presidência na British Association for the Advancement of Science com um discurso sobre os papéis que cabiam aos museus de história natural, no século que se avizinhava.

$\mathrm{O}$ artigo de Flower foi traduzido para o francês, uma semana depois do seu pronunciamento, e publicado na seção "Enseignement des sciences", na primeira página da Revue Scientifique (Revue Rose), uma das principais revistas de divulgação científica francesa da época. Foi também traduzido, diretamente da versão reproduzida pelo Times, no dia seguinte de seu pronunciamento, para o espanhol e publicada na Revista del Museo de La Plata (1890-1), o que nos dá um outro indício da amplitude de sua divulgação. Na versão de Moreno, bem como na da Revue Scientifique (a que Moreno atribuía graves erros e supressões), faltavam os parágrafos iniciais e finais do discurso, em que Flower fazia menção aos presidentes anteriores e à sua própria nomeação para a direção da Associação, bem como ao renome e importância da mesma no civilised world (Flower, 1890-1). Nos parágrafos finais omitidos, Flower mencionava alguns versos que ressaltavam o plano divino que sustentava a perfeição da evolução das formas vivas da natureza.

No contexto local das disputas científico-institucionais entre os naturalistas argentinos, Florentino Ameghino também comentaria o discurso de Flower na seção "Revista crítica y bibliográfica" de sua Revista Argentina de Historia Natural, em abril de 
1891. O conhecido paleontólogo, que havia colaborado com Moreno para a fundação do Museo de La Plata, e aí trabalhara por um curto período, considerou o discurso de Flower 'magistral', uma obra "verdaderamente digna del o renombre del sabio que la ha producido". Recomendava em tom irônico, em uma crítica direta a Moreno, que o impedia mesmo de entrar no museu, que se inspirasse especialmente nas recomendações de Flower quanto ao "fin específico y planeado" de cada museu, bem como na importância maior que Flower atribuía ao 'conservador' do museu, em relação ao edifício, às estantes e às próprias coleções. Advogando em causa própria, já que construíra sua trajetória de paleontólogo sem o reconhecimento oficial de um posto de trabalho nos museus argentinos, Ameghino (1891, p. 113-4) ressaltava as idéias de Flower de que o curador e seus ajudantes eram a "vida y el alma de la institución", e acrescentava que "en nuestros museos, es lo último que se piensa".

Em 1898, o próprio Flower reproduziu esse discurso com o nome "Museum organization", na abertura de Essays on museums and other subjects connected with Natural History, coletânea com artigos de sua autoria (Flower, 1996). Esta obra destaca a relação estreita entre a construção da história natural e os espaços museológicos que justamente abrigaram tais disciplinas. Entre os trabalhos publicados, há sete sobre museus, oito sobre biologia geral e cinco sobre antropologia. Nessa edição, o discurso de Flower se apresenta dividido nos seguintes subitens: Escolha do tema, Museus da Antiguidade e da Idade Média, Os termos história natural e naturalista, Definição de um museu de história natural, Subdivisões das ciências representadas em um museu de história natural, Objetos do museu, Pesquisa e instrução, Métodos de organização de especimens para estudo e para exibição pública, Etiquetas, Textos-guia e catálogos, Problemas biológicos atuais, Evolução dos seres humanos, Seleção natural, Sobrevivência do mais apto e Dificuldades que emergem da imperfeição do nosso conhecimento.

No fim do século XIX, o recém-inaugurado Museu de La Plata, integrante desse circuito de museus que se ampliava, também se apropriaria desses discursos. Moreno publicou Flower com a explícita intenção de estabelecer seu referencial teórico sobre museus, buscando diferenciar seu moderno museu do velho gabinete de estudos mantido desde o ano de 1862 pelo consagrado naturalista prussiano German Burmeister em Buenos Aires (Lascano González, 1980). O ideal de Moreno era consolidar um museu tal qual Flower descrevia em seu discurso. "Este estudio encierra todo el plan de nuestro museo", afirmava Moreno em seu artigo "Rápida ojeada sobre su fundación y desarrollo", destacando a influência marcante do trabalho de Flower como curador do Real College of Surgeons de Londres, em sua proposta de museu (Moreno, 1890-1, p. 29). 
Durante sua permanência na Europa em 1880, Moreno conheceu Flower no Real College of Surgeons e encantou-se com seu trabalho na organização do museu, na preparação dos objetos, reconhecendo na primeira publicação do Museu de La Plata que "su obra me abrió los ojos sobre lo que debia ser un museo". Moreno (1890-1a, p. 29), no entanto, não ignorava que as condições de estabelecimento de museus na Argentina eram completamente diferentes das européias:

Cuando trazé el plan de este establecimiento tuve siempre presente lo que allí ví pero no siempre se dispone de los elementos necesarios, ni siempre es el medio igual. Lo que era posible en Londres, fué imposible exigirlo de la Plata, la ciudad que no existía cuando admiraba aquellas colecciones y hube de dar tiempo al tiempo para poner en práctica mi programa.

Perseguindo na prática os princípios organizacionais de Flower, Moreno identificava o Museu de La Plata, nos seus primeiros anos, como "ya nacido" - termos de Flower - mas precisando ainda de forças para crescer. Em "Rápida ojeada...", verdadeiro relatório dos primeiros cinco anos de atividades do museu, Moreno repetidamente salientava o caráter incipiente da sua obra, atribuindo-o à falta de tempo, orçamento e pessoal. Por isso considerava, reproduzindo as palavras de Flower, que "la verdad es que recién ha empezado la tarea". Portanto, muitas das situações assinaladas no discurso de Flower como não desejáveis ainda estavam presentes no Museo de La Plata, "no por falta de buena voluntad sino de elementos" (Moreno, 1890-1a, p. 29). Inserido no clima de confiança extrema nas possibilidades futuras do país, em que viviam "los yankees del sur" no final do século XIX, o otimismo de Moreno era grande. Estava construindo uma grande instituição para uma grande nação, esperando abrigar, no museu da cidade de província construída no deserto, reuniões científicas internacionais, que fariam jus ao passado e ao futuro austral americano:

Con todo esto, el Museo de la Província de Buenos Aires llenará su programa, sirviendo á nacionales y estranjeros en bien de las ciencias y de su progreso que tanto debe contribuir á que estas regiones americanas sean grandes en el futuro. Una vez que los hombres de estúdio del Norte tengan conocimiento de los materiales que en estos países se han reunido para el mayor adelanto de las ciencias, hemos de ver iniciarse una reaccion favorable hácia Sud-América, bajo el punto de vista intelectual (Moreno, 1890-1, p. VI). 


\section{"The new museum idea"}

Flower inicia seu discurso fazendo uma revisão da origem e da evolução dos museus e assinalando a importância de sua transformação em espaços públicos vinculados ao Estado, o que lhes conferiria um novo papel no fim do século XIX: colaborar com a educação e com a investigação científica. A importância dada a essa dupla função dos museus é central no discurso de Flower. Em outro artigo, "Modern museums", ele assinala que esta dupla função já havia sido definida, em 1864, por John Edward Gray, então diretor do Zoological Department do British Museum, em um discurso na British Association.

Pesquisa científica e educação constituíram de fato a articulação, na maioria das vezes contraditória, que marcou o mundo dos museus de ciências naturais na transição para o século XX (SheetsPyenson, 1988; Lopes, 2003). 'Musealizada' nas próprias organizações das exposições, tal articulação fundamentou uma vasta discussão sobre concepções e propostas de separação de coleções de pesquisa e as de instrução do público leigo.

A versão nacional dessas contradições foi claramente explicitada pelo discurso inaugural do Museu Paulista de Hermann von Thering (Lopes, 1997). Seguindo os princípios não de Flower, mas de George Brown Goode (1889) - com quem Ihering se correspondia -, defendeu a especialização dos museus para a superação da crise por que passavam. Thering, naquele discurso, excluiu o Museu Nacional de seus padrões de cientificidade. No primeiro volume da Revista do Museu Paulista, no item "Bibliographia" em Os museus da América do Sul, Ihering (1895, p. 233) reafirmou sua posição:

Não é pequeno talvez o número de museus que já existem na América do Sul. Para nós, porém, só podem ser de interesse os museus organizados sobre base científica e com pessoal competente. De museus que correspondem a estas exigências temos dois no Brasil - os de São Paulo e do Pará -, dois na República Argentina - o de Buenos Aires e de La Plata -, um em Montevidéu e um no Chile, em Santiago.

Flower dedicou grande parte do seu discurso a identificar as questões centrais que deveriam regular a organização de exposições de um museu que pretendesse cumprir seus objetivos de instrução e investigação. As mesmas recomendações foram retomadas e sintetizadas em seu discurso na Museums Association, em 1893, e tornaram-se os princípios básicos do que se consagrou como a 'new museum idea' (Flower, 1996).

Parte da justificativa para a construção dos novos museus que se organizaram no final do século XIX, na Alemanha, por exemplo, se apoiava justamente nessas idéias, 'musealizadas' no princípio 
segundo o qual as coleções de pesquisa deveriam ser absolutamente separadas daquelas destinadas à exibição pública (Nyhart, 1997). Atribuída a diferentes cientistas de museus por pesquisadores do tema, tal idéia se generalizou amplamente na época. Ihering afirmava seguir, desde o início da organização do Museu Paulista, o destacado zoólogo do Museu de Kiel, Karl Möbius (1825-1908), em seu princípio de separação de coleções de estudo e de exibição (Lopes, 1997), cuja paternidade da idéia também é reconhecida por Bragança Gil (1994), a partir de outros referenciais de estudo. Sheets-Pyenson (1988) atribuíra a Agassiz, em seu arranjo do Museum of Comparative Zoology (MCZ), a prioridade na formulação da proposição.

De qualquer forma, incorporada à obra de Flower, esta se tornaria referencial seguro para o mundo dos museus, até pelo menos o final da década de 1930, particularmente no caso dos naturalistas do Museu Nacional do Rio de Janeiro. Ainda em 1939, encontramos referências a Flower no relatório que Bertha Lutz, zoóloga do Museu Nacional do Rio de Janeiro, encaminhou a Roquette Pinto, então diretor do museu, sobre sua viagem de estudos aos Estados Unidos. Sem desconhecer que o Deutsches Museum, de Munique, era considerado na época "o pioneiro e realizador máximo da teoria moderna do Museu", Bertha Lutz se referia a "uma nova teoria do Museu, sintetizada pela primeira vez pela expressão the new museum idea", por Flower, em Essays on museums, que propugnava como função do museu "difundir a instrução e contribuir para o recreio intelectual da massa do povo, e proporcionar ao pesquisador científico o ensejo de examinar e estudar detidamente todos os espécimes que constituíam as coleções do Museu" (Lutz, 1939).

Com precisão, no discurso publicado por Moreno, Flower discute as questões centrais na época de especialização da história natural. Considerava feliz a introdução da palavra biologia, já aceita de modo geral, e a definia como os estudos dos organismos que se distinguem por possuírem o princípio vital. O termo ‘história natural', profundamente enraizado na linguagem comum e que fora aplicado tradicionalmente a todos os fenômenos do universo independentes da ação do homem, estava ficando vago e indefinido. Propunha, então, voltar ao seu sentido original e definia um museu "puramente de historia natural" como aquele que tivesse "la colección de objetos que ilustren las producciones naturales de la tierra, y en el más amplio y verdadero sentido, todas las ciencias que tratan de los fenómenos naturales que puedan representarse por ejemplares de Museo" (Flower, 1890-1, p. 8). Refletindo também sobre a supremacia da zoologia em muitos dos museus de história natural do fim do século XIX, comentava a confusão do uso do termo 'naturalista' que, "de maneira irracional", estava sendo utilizada como sinônimo de zoólogo. 
2 Para uma análise dessa discussão no caso dos museus brasileiros, ver Gualtieri (2001).
Flower (1890-1, p. 19) dedica a última parte de seu discurso aos novos desafios teóricos colocados pelas "leyes que rijen la evolución de los seres organizados", aos "problemas que ajitan los espíritus de todos los biologistas de la época actual, y cuya solución es esperada con ávido interés por un vasto círculo, círculo que coincide con la inteligencia y la instrucción del mundo". Depositando sua confiança na doutrina que estabelecia que "todas las formas existentes de la vida derivan de otras formas por un progreso natural de descendencia con modificaciones" , ponderava a respeito das discussões então contemporâneas sobre os mecanismos de ação das forças evolutivas, não deixando de mencionar Wallace, Huxley, Weismann, entre outros cientistas envolvidos nessas discussões. No âmbito dos debates evolucionistas, cabia aos museus desempenhar o papel de loci essenciais à pesquisa. ${ }^{2}$ Aprimorá-los permitiria avançar tais estudos: "Principiamos á saber algo de la forma y de la estructura de los cuerpos organizados. Nuestros museos, cuando sean mas completos y mejor ordenados, nos enseñarán mas aún sobre esto" (Flower, 1890-1, p. 23).

De fato, o darwinismo não só revigorou os museus da época como levou à criação de muitos outros, ao contrário do que quiseram fazer valer histórias consideradas como padrões das ciências da vida, que deram um peso exagerado à idéia da transformação de museus em laboratórios, da substituição da história natural pela biologia. Evidentemente, a história natural, de disciplina abrangente que era, passou a ser, no fim do século, apenas uma das várias orientações que um biólogo poderia seguir. Na verdade, exatamente quando a historiografia considerou que a biologia saía do museu, afastando-se da sistemática e da história natural, voltando-se para pesquisas de laboratório, os museus experimentaram um crescimento explosivo por todo o mundo. É certo que, enquanto os museus continuavam a conservar suas coleções protegidas da influência desastrosa da luz que danificava as cores dos especimens, novos e especiais prédios eram construídos para os laboratórios dos microscopistas, que exigiam enormes janelas para a ampla iluminação.

Apresentar tais mudanças como 'a' transformação institucional em biologia é não apreender a visão do todo, chama a atenção Lynn Nyhart (1997, p. 435). Nas diversas universidades americanas ou alemãs em que os novos laboratórios foram construídos, a pesquisa em história natural continuou e, em parte, dentro dos novos laboratórios. Os museus de história natural não desapareceram, mas ganharam autonomia em relação aos departamentos de zoologia das universidades, como no exemplo significativo do Museum of Comparative Zoology, em Harvard (Winsor, 1991). É também a essa discussão que se refere Flower, quanto à confusão entre os termos naturalista e zoólogo. 
3 Para considerações mais amplas sobre esses parâmetros nos museus latinoamericanos, particularmente sobre suas relações com as práticas educacionais, temos como referências de análise os comentários de Podgorny (1995) sobre a importância do uso da 'imagem e das coisas' na educação, no final do século XIX, baseadas nas idéias de Froebel.
Outros temas que mereceram atenção de Flower foram a divisão das coleções do British Museum em antropologia e arqueologia e a construção de um novo prédio para as de história natural em torno de 1881, refletindo de novo a perda de hegemonia científica que sofreu a área; a separação da paleontologia como subárea da biologia e sua incorporação pela geologia e as promissoras descobertas de mamíferos cretáceos de Othoniel Marsh, que abriam campos inusitados de investigação para a história da vida. Tais questões, entre outras, eram também as preocupações centrais dos museus latino-americanos do final do século. Assim se explicam a tradução, a publicação e as referências a esse discurso na Argentina. Ciências como paleontologia, arqueologia, etnografia e antropologia ocupavam posições de destaque nas discussões de então, apelando à memória, à origem, à civilização e à construção de propostas das nacionalidades (Lopes e Podgorny, 2000).

No que se refere à educação, Flower salientava justamente a importância de se "reconocer el valor de esas instituciones como agentes del gran movimiento educacional de nuestra época". Para compreender sua visão, cabe refletir sobre o tipo de educação de que está falando. O papel educacional dos museus em si não era, mesmo naquela época, uma questão nova. Se desde as coleções renascentistas já estavam implícitas sua missão educativa (Findlen, 1996), a partir da organização do Muséum d'Histoire Naturelle de Paris, gabinetes, museus não podem mais ser encarados apenas como propriedades de príncipes ou eruditos e consolida-se o modelo dos museus a serviço da instrução pública, apoiados na concepção de que a observação direta é a única fonte de conhecimento (Spary, 1997).

Assim, as exposições dos museus ampliam seu público, consolidam um papel educativo substancial ao permitirem a confrontação direta do público com os objetos. Esta idéia é retomada no novo contexto vitoriano do discurso de Flower, sustentando novamente a importância da aprendizagem por meio da percepção visual para a incorporação das massas urbanas aos processos civilizadores do final do XIX (García e Podgorny, 2001). Longas séries, peças e esqueletos completos foram fundamentais também para atrair o público, que se supunha incapaz de compreender globalmente um animal ou uma cultura apenas pela observação dos fragmentos, que podiam bastar ao especialista. Nessa época, em que a 'lição das coisas' se colocava como condição indispensável para a educação da juventude e das populações urbanas iletradas, todos os museus da América Latina ressaltaram a importância também dos fins educativos de suas exposições. ${ }^{3}$

Flower considerou que os museus estavam destinados a duas classes de 'homens'. Por um lado, os museus deveriam ser úteis aos estudiosos das ciências que desejassem 'progredir' em uma área 
do conhecimento. Assim, uma das funções da instituição era a preservação das coleções e, particularmente, dos materiais considerados imprescindíveis para a comparação e a descrição das formas da natureza. Esta função, uma vez que os museus se vincularam ao Estado, remetia diretamente às propostas de construção de identidades nacionais apoiadas em políticas de preservação e valorização de patrimônios naturais e culturais, o que foi extremamente enfatizado no período pelos museus argentinos (Podgorny, 2000). Por outro lado, essas instituições deveriam se voltar a um público que "no tiene ni el tiempo, ni las ocasiones" (Flower, 1890-1, p. 12), mas gostaria de conhecer os caminhos da ciência, mesmo sem integrá-los. Para que o museu se tornasse um poderoso instrumento facilitador da instrução desse público - que se esperava fosse cada vez maior -, a organização das exibições assumia um papel central, e o tema ocuparia boa parte do discurso de Flower.

Moreno, que afirmava ter organizado as exposições do Museo de la Plata seguindo princípios darwinistas, de modo que "sus galerias debian guardar sin solucion de continuidad desde el organismo mas simples y primitivo hasta el libro que lo describe", desde o primeiro momento incorporara em seus planos a idéia de um museu que exercesse a dupla função de pesquisa e instrução pública. Correspondendo, portanto, aos ideais de Flower, o de La Plata deveria ser "un museo de esposición, al mismo tiempo que un establecimiento de estudio" (Moreno, 1890-1891, p. 39, 31). Entretanto, havia prioridades: "El Museo de instrucción, para el cual se reunen tantos materiales, no será organizado debidamente hasta que lo esté el de 'esposición', lo que es lógico" (Moreno, 1890-1891, p. 34). Seu projeto previa a construção de novas salas para abrigar estudantes em seus locais de trabalho e, uma vez superadas as limitações financeiras existentes, o ideal de Flower seria realizado.

O 'museu de exposição' de Moreno visava a atrair o público que ainda não valorizava os museus por desconhecimento ou por falta de atrativos. O poder de atração dos objetos deveria ser um critério a se priorizar na seleção do material a ser exposto, e sua disposição nas salas deveria realizar-se de forma a poderem ser apreciados pelo público.

La primera impresión, si esta no se impone por brillantes colores o bellas formas, es pálida y muchas veces se abandona; solo el contraste la excita, atrae la refleccion que resulta del porqué ese objeto sin vista se considera de mayor aprecio que los que tiene delante, y poco á poco, lentamente, la luz se hace en su espíritu, y ante este, un fragmento de hueso, una piedra informe, un tiesto viejo de origen y de tiempo desconocido, le revela fenómenos no soñados, que alimentan la fantasia humana, madre de todos los conocimientos (Moreno, 1890-1891, p. 31-2). 
A confiança de Moreno no poder educativo de suas exibições era tal que supunha que estas tinham o poder de afastar o 'público inculto' de lugares e atividades consideradas inapropriadas. Atento à opinião do público que começava a freqüentar o Museo de La Plata e, em função de suas próprias observações, afirmava que "muchos concurrentes a este establecimiento vuelven con frecuencia y que algunos lo visitan todos los domingos" e que o museu "se ha convertido en un lugar de amena reunión" (Moreno, 1890-1891, p. 33).

Cumprir sua função na pesquisa e na educação laica e popular simbolizando como museu de história natural o domínio do homem sobre seu meio natural e as potencialidades econômicas do território - seria fundamental também para o Museu de La Plata dar sua contribuição para o projeto liberal de nação que se imaginava construir na Argentina em fins do século XIX (Perez Gollán, 1995).

Entretanto, atingir o museu ideal de Flower, combinando as funções científicas e educativas dos museus às vésperas do novo século, demandava seguir instruções precisas que abrangiam desde a boa administração até as dimensões das instalações e a separação das coleções. Do ponto de vista da investigação, as coleções deveriam ser "no solo escesivamente numerosos, sino que deben ser presentados de manera que permitan su examen y la comparacion de cerca y fácilmente" (Flower, 1890-1, p. 13). Para as exposições públicas, em contrapartida, recomendava-se especialmente não sobrecarregar as vitrines e selecionar cuidadosamente os objetos a serem expostos:

(...) una esposicion publica para ser instruitiva é interesante no debe jamás ser recargada. No hay verdaderamente razon para que asi sea. Tal esposición, hecha sobre pequeña o grande escala, no puede contener sino ejemplares elejidos, en vista de las necesidades de una clase especial personas que deben visitar las galerias, y el numero de piezas debe se proporcionado al espacio disponible (Flower, 1890-1, p. 16).

Às novas galerias que visavam a oferecer aos visitantes as condições ideais para compreender as novas perspectivas científicas e a recém-descoberta 'ordem da natureza', era fundamental abandonar as velhas concepções de "cuarto de reserva ó un almacén" (Flower, 1890-1, p. 19). Não foram esquecidos cuidados com iluminação, poeira e umidade nem com a clareza na identificação dos objetos. Flower recomendava o uso de etiquetas para informações sucintas que deveriam ser completadas por catálogos e guias. $\mathrm{O}$ espaço, tão caro aos museus, aparecia como um requisito indispensável para uma adequada contemplação dos objetos. Esse autor previa que um museu ideal viesse a ter ainda menos peças em exi- 
bição, de modo que "el vistante pueda darse cuenta de la maravillosa complexidad de las proporciones que pone cada especie en relacion com el medio que la rodea" (Flower, 1889, p. 17).

Moreno assinalava uma e outra vez, na descrição do Museo de La Plata, que sua organização inicial era em certa medida transitória. A necessidade de construir novos espaços era mencionada permanentemente como requisito para um melhor ordenamento das coleções e condição para poder conseguir seu museu ideal.

Desgradaciadamente cuando concebi este establecimiento no pude darle las proporciones que debio tener, habiendo sido consideradas como exageradas aún las actuales, lo que impide que pueda ser tomado como un tipo perfecto de Museo. No dudo que llegará bien pronto el dia en que la importancia de sus colecciones hará necesaria su modificación ensanchando sus galerías y completando mi plan. Recien entonces podrá prestar los servicios de un museo en el amplio sentido de esta palabra (Moreno, 18901891, p. 39).

A necessidade de renovação e de cuidado permanente com as coleções era outro dos requisitos indispensáveis de um bom museu. Para solucionar o problema da deterioração inevitável dos exemplares expostos, Flower (1890-1, p. 11) propunha contar com "una serie suplementaria de ejemplares comunes que se reemplazarían facilmente cuando se deterioren, para el uso de profesores y discípulos". No início do século XX, sua frase amplamente divulgada, "Un museo se asemeja á un organismo viviente; exije atentos y constantes cuidados", seria repetida por João Batista de Lacerda, na direção do Museu Nacional do Rio de Janeiro (Lopes, 1997), e por Alfonso Pruneda, em seu estudo sobre os museus apresentado para a Sociedad Mexicana de Geografia y Estatística do México, como argumento para defender a necessidade de renovação periódica das coleções.

O museu ideal de Flower deveria reunir em uma só instituição as coleções nacionais que ilustravam as diferentes 'ramas' da ciência e da arte "colocándolas en tal orden y yustaposición que sus relaciones mutuas sean visibles y que las propiedades de cada una puedan servir á elucidar todas las otras" (Flower, 1890-1, p. 8). Para cumprir esse ideal, o Museo de La Plata, como fiel herdeiro dos museus de história natural, se propôs também a incorporar o homem e sua obra, como expressão máxima da evolução das espécies. Por isso, sua exposição começava com as primeiras formas de vida conhecidas e terminava nas salas de belas-artes, incorporando até mesmo uma locomotiva, 'La Porteña', símbolo do progresso técnico argentino da transição do século. 
*Agradecimentos: a Alda Heizer, pela referência da Revue

Rose; a Magali Romero e Jaime Benchimol, pelo documento de Bertha Lutz; ao CNPq e à Capes, pelo apoio às pesquisas desenvolvidas pelas autoras.

\section{Considerações finais}

Os comentários sobre as concepções de ciências e educação dos construtores de museus da transição para o século XX evidenciam o quanto a pesquisa científica, os rumos que tomavam a história natural e as exigências em torno da necessidade de ampliar o alcance da educação popular foram dimensões inseparáveis das funções que se atribuíam aos museus no novo século. Para isso é necessário adotar um referencial teórico que discuta o significado da comunicação pública dos museus, a dualidade de papéis que assumiram como instituições científicas e como espaços privilegiados de formação das incipientes massas urbanas - um processo que se acelera e se aprofunda para o início do século XX na América Latina, incluindo desde museus escolares até propostas explicitamente relacionadas à educação e a práticas técnico-industriais.

Em diferentes contextos, conotações profundamente elitistas e de marcadas divisões sociais se mesclaram com propósitos de ações democráticas e acesso generalizado à educação, em que os museus se apresentaram como instituições essenciais de comunicação e controle. As atuações educacionais e científicas, os papéis culturais, ideológicos, políticos dos museus latino-americanos necessariamente devem ser compreendidos de forma não dissociada dos quadros conceituais mais amplos dos processos museais, científicos e comunicacionais que acompanharam os museus públicos desde suas origens.

A perspectiva histórica também sobre o tema da educação e da comunicação em museus pode ser uma contribuição relevante no sentido de superar dificuldades e ampliar proposições como as de Morales-Moreno (1994). Na verdade, o acúmulo de experiências na área, os trabalhos de avaliação sobre práticas educativas, os estudos sobre públicos em curso no país e na América Latina já estão exigindo novas reflexões que proponham formas inovadoras de ação diante dos desafios apresentados atualmente para os museus.

\section{REFERÊNCIAS BIBLIOGRÁFICAS}

Ameghino, $\mathrm{F}$. abr. 1891

Bragança Gil, F. 1994

Brefe, A. C. F. 2000

Coleman, L. V. 1939
Los museos de historia natural.

Revista Argentina de Historia Natural, v. 1, n. 2, p. 113-4.

Museu de Ciência da Universidade de Lisboa, sua caraterização à luz da museologia das ciências. Lisboa, Museu de Ciência.

Um lugar de memória para a Nação: o Museu Paulista reinventado por Affonso d' Esgragnolle Taunay (1917-1945). Tese de doutoramento. Instituto de Filosofia e Ciências Humanas, Unicamp, São Paulo.

The museum in America: a critical study.

Washington D. C., The American Association of Museums. 3 v. 


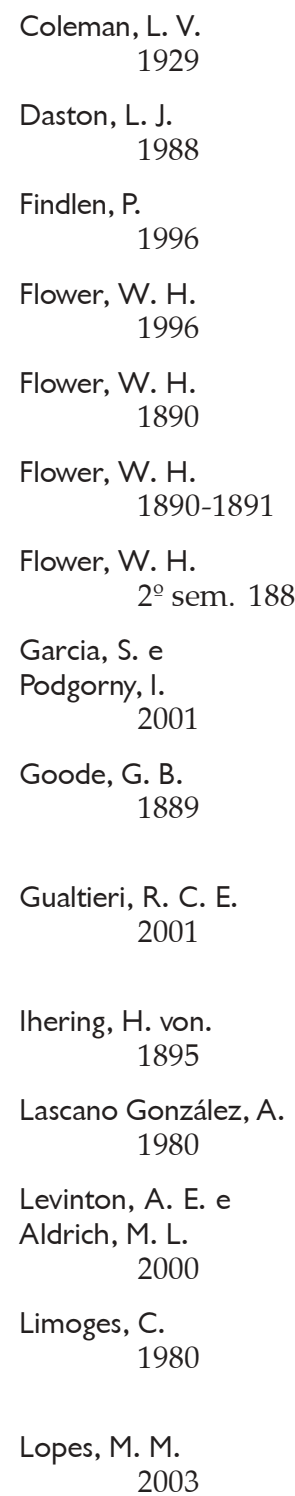

Lopes, M. M. 2002

Lopes, M. M. 1997

Lopes, M. M. e Podgorny, I. 2000
Directory of museums in South America.

Washington D. C., The American Association of Museums.

The factual sensibillity reviews on artifact and experiment. ISIS, 79, p. 452-70.

Possessing nature: museums, collecting, and scientific culture in early modern Italy. Berkeley, University of California Press.

Essays on museums and other subjects connected with natural history.

Londres, Routledge-Thoemmes Press. (1. ed., 1898)

Adress by professor W. H. Flower. Report of the meeting of the British Association for the Advancement of Science. Londres.

Los museos de historia natural.

Revista del Museo de La Plata, I, p. 2-25.

Lés musées d'histoire naturelle.

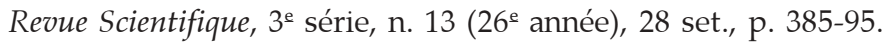

Pedagogía y nacionalismo en la Argentina: lo internacional y lo local en la institucionalización de la enseñanza de la arqueología. Trabajos de Prehistoria, v. 58, n. 2, p. 9-26.

Museum-history and museums of history. In: Adams, H. B. (ed.).

Papers of the American Historical Association. v. 3.

Nova York, Putnam's Sons, p. 497-520.

Evolucionismo e ciência no Brasil: museus, pesquisadores e publicações, 1870-1915. Departamento de História, Faculdade de Filosofia, Letras e Ciências Humans, Universidade de São Paulo.

Bibliographia - a) Os museus da América do Sul. Revista do Museu Paulista, I, p. 233-45.

El Museo de Ciencias Naturales de Buenos Aires: su historia. Buenos Aires, Ediciones Culturales Argentinas.

India: a case study of natural history in a colonial setting. In: Ghiselin, M. T. e Levinton, A. E. (eds.). Cultures and institutions of natural history. São Francisco, California Academy of Sciences, p. 51-80.

The development of the Muséum d'Histoire Naturelle of Paris, c. 1800-1914. In: Fox,. R. e Weisz, G. (eds.). The organization of science and technology in France, 1808-1914. Cambridge. Cambridge Univ. Press, p. 211-40.

Museus e educação na América Latina: o modelo parisiense e os vínculos com as universidades. In: Gouvêa, G. et al. (orgs.). Educação e museu: a construção social do caráter educativo dos museus de ciências.

Rio de Janeiro, Fundação de Amparo à Pesquisa do Estado do Rio de Janeiro (Faperj), Editora Access, p. 63-82.

Latin American Museums: comparative studies and links.

In: Dorikens, M. Scientific instruments and museums. Proceedings of the $\mathrm{XX}^{\text {th }}$ International Congress of History of Science, v. XVI. Bélgica, Brepols Publishers, p. 221-35.

O Brasil descobre a pesquisa cientifica: os museus e as ciências naturais no século XIX. São Paulo, Hucitec.

The shaping of Latin American museums of natural history, 1850-1890. Osiris, 15, p. 108-18. 
Lutz, B. J. M. 1939

Morales-Moreno, L.G. 1994

Moreno, F. P. $1890-1891$

Nyhart, L. K. 1997

Oroz, J. J. 1990

Pearce, S. 1989

Perez Gollán, J. A. 1995

Podgorny, I. 2000

Podgorny, I. 1995

Schnitter, C. 1996

Sheets-Pyenson, S. 1988

Spary, E. 1997

Winsor, M. P. 1991
Relatório apresentado ao Exmo. Sr. Professor Dr. Roquette Pinto M. D. Director do Museu Nacional sobre o papel educativo dos museus americanos. Rio de Janeiro, Museu Nacional.

Origenes de la museología mexicana: fuentes para el estudio histórico del Museo Nacional 1780-1940. México, Universidad Iberoamericana.

Revista del Museo de La Plata, tomo I.

Natural history and "new" biology. In: Jardine, N. et al. (eds.). Cultures of natural history. Cambridge, Cambridge University Press, p. 426-43.

Curators and culture: the museum movement in America, 1740-1870. Tuscaloosa-Londres, The University of Alabama Press.

Museum studies in material culture. In: Pearce, S. (org.). Museums studies in material culture. Londres, Leicester University Press.

Mr. Ward en Buenos Aires: los museos y el proyecto de nación a fines del siglo XIX. Ciencia Hoy, 28, p. 52-8.

El argentino despertar de las faunas y de las gentes prehistóricas: coleccionistas, museos y estudiosos en la Argentina entre 1880 y 1910. Buenos Aires, Eudeba/ Libros del Rojas.

De razón a facultad: ideas acerca de las funciones del Museo de La Plata entre 1880 y 1920. Runa, v. 22, p. 89-104.

Le développement du Muséum National d'Histoire Naturelle de Paris au cours de la seconde moitié du XIXe siècle: "se transformer ou périr". Rev. Hist. Sci., v. 49, n. 1, p. 53-97.

Cathedrals of science: the development of colonial natural history museums during the late nineteenth century. Montreal, McGill-Queen's Univ. Press.

Le spectacle de la nature: contrôle du public et vision républicaine dans le muséum jacobin. In: Blanckaert, C. et al. (coords.). Le muséum au premier siècle de son histoire. Paris, Éditions du Muséum National d'Histoire Naturelle, p. 457-79.

Reading the shape of nature: comparative zoology at the Agassiz Museum. Chicago/Londres, Chicago University Press. 